Conference Article

\title{
Chaotic effect of constant marginal cost in nonlinear duopoly game with heterogeneous players
}

\author{
G. Sarafopoulos
}

Department of Economics, Democritus University, Komotini 69100, Greece

\begin{abstract}
In this study we investigate the dynamics of a nonlinear discrete-time duopoly game, where the players have heterogeneous expectations linear demand and cost functions. Two players with different expectations are considered; one is boundedly rational and the other thinks with adaptive expectations. We show that the model gives more complex chaotic and unpredictable trajectories as a consequence of change in the marginal costs of the players. The chaotic features are justified numerically via computing Lyapunov numbers, sensitive dependence on initial conditions and the box dimension of the chaotic attractor.
\end{abstract}

Keywords: Discrete dynamical system; Cournot duopoly games; Complex dynamics; Heterogeneous expectations; Box dimension

\section{Introduction}

An Oligopoly is a market structure between monopoly and perfect competition, where there are only a few number of firms in the market producing homogeneous products. The dynamic of an oligopoly game is more complex because firms must consider not only the behaviors of the consumers, but also the reactions of the competitors i.e. they form expectations concerning how their rivals will act.

Cournot, in 1838 [9] has introduced the first formal theory of oligopoly. He treated the case with naive expectations, so that in every step each player (firm) assumes the last values that were taken by the competitors without estimation of their future reactions.

Expectations play an important role in modelling economic phenomena. A producer can choose his expectations rules of many available techniques to adjust his production outputs. In this paper we study the dynamics of a duopoly model where each firm behaves with different expectations strategies. This kind of beliefs is common in real world problems such as economic, biology and social sciences problems. We consider a duopoly model where each player forms a different strategy in order to compute his expected output. We take firm 1 to represent a boundedly rational player while firm 2 has adaptive expectations. Each player adjusts his outputs towards the profit maximizing amount as target by using his expectations rule.

Some authors considered duopolies with homogeneous expectations and found a variety of complex dynamics in their games, such as appearance of strange attractors

\footnotetext{
* E-mail address: gsarafop@ierd.duth.gr

ISSN: 1791-2377 @ 2015 Kavala Institute of Technology. All rights reserved.
}

$[1,2,5,13,18,20]$. Also models with heterogeneous agents were studied $[3,4,10,21]$. The main purpose of this paper is to investigate the effect of the marginal cost in the dynamic behavior of the duopoly examined in Agiza and Elsadany [3]; representing two firms using heterogeneous expectations rules. The plan of the paper is as follows: In Section 2, the dynamics of a duopoly game with boundedly rational player and adaptive player is analyzed. The existence, local stability and bifurcation of the equilibrium points are also analyzed. In Section 3 numerical simulations are used to show complex dynamic via computing Lyapunov numbers, sensitive dependence on initial conditions and the box dimension of the chaotic attractor is calculated.

\section{The model}

In oligopoly game players can choose simple expectation rules such as naïve or complicated as adaptive expectations and bounded rationality. The players can use the same strategy (homogeneous expectations) or can use different strategy (heterogeneous expectations). In this study we consider heterogeneous players such that each player think with different strategy to maximize his output. Two different players expectations are proposed; boundedly rational player and adaptive player.

We consider a simple Cournot-type duopoly market where firms (players) produce homogeneous goods which are perfect substitutes and offer them at discrete-time periods $t=0,1,2, \ldots$ on a common market. At each period $\mathrm{t}$, every firm must form an expectation of the rival's output in the next time period in order to determine the corresponding profit-maximizing quantities for period $t+1$. 
The inverse demand function of the duopoly market is assumed linear and decreasing:

$P=f(Q)=a-b\left(q_{1}+q_{2}\right)$

where $Q=q_{1}+q_{2}$ is the industry output and $a, b>0$. It is supplied by two firms with linear cost function

$$
C_{i}\left(q_{i}\right)=c_{i} q_{i}, \mathrm{i}=1,2
$$

where $c_{i}$ is the marginal cost of ith firm. With these assumptions the single profit of ith firm is given by

$$
\Pi_{i}\left(q_{1}, q_{2}\right)=q_{i}(a-b Q)-c_{i} q_{i}, \mathrm{i}=1,2
$$

Then the marginal profit of ith firm at the point $\left(q_{1}, q_{2}\right)$ of the strategy space is given by

$$
\frac{\partial \Pi_{i}}{\partial q_{i}}=a-c_{i}-2 b q_{i}-b q_{j}, \mathrm{i}, \mathrm{j}=1,2, \mathrm{i} \neq \mathrm{j}
$$
form

This optimization problem has unique solution in the

$$
q_{i}=g\left(q_{j}\right)=\frac{1}{2 b}\left(a-c_{i}-b q_{j}\right)
$$

\subsection{Duopoly game with heterogeneous players}

The first firm decides to increase its production if it has a positive marginal profit, or decreases its production if the marginal profit is negative ( boundedly rational player). Then the dynamical equation of player 1 has the form

$q_{1}(t+1)=q_{1}(t)+u q_{1}(t) \frac{\partial \Pi_{i}}{\partial q_{1}}, \mathrm{t}=0,1,2, \ldots$

where $u$ is a positive parameter which represents the relative speed of adjustment. Another expectation rule that firm can use to revise their beliefs according to the adaptive expectations rules.

If the firm 2 think with adaptive expectations it computes its outputs with weights between last period's outputs and his reaction function $g\left(q_{1}\right)$. Hence the dynamic equation of the adaptive expectation player 2 has the form

$$
q_{2}(t+1)=(1-v) q_{2}(t)+v g\left(q_{2}(t)\right)
$$

where is $v \in[0,1]$ is a speed of adjustment of adaptive player. Hence the dynamic duopoly game in this case is formed from combining Eqs. (6) and (7). Then the dynamical system of heterogenous players is described by

$$
\left\{\begin{array}{l}
q_{1}(t+1)=q_{1}(t)+u q_{1}(t)\left(a-2 b q_{1}(t)-b q_{2}(t)-c_{1}\right) \\
q_{2}(t+1)=(1-v) q_{2}(t)+\frac{v}{2 b}\left(a-c_{2}-b q_{1}(t)\right)
\end{array}\right.
$$

We will focus on the dynamics of the system (8) to the parameters $c_{i}, i=1,2$.

\subsection{Equilibria and local stability}

The equilibria of the dynamical system (8) are obtained as nonnegative solutions of the algebraic system

$$
\left\{\begin{array}{l}
q_{1}(t)\left(a-2 b q_{1}(t)-b q_{2}(t)-c_{1}\right)=0 \\
a-c_{2}-2 b q_{2}(t)-b q_{1}(t)=0
\end{array}\right.
$$

which obtained by setting $q_{i}(t+1)=q_{i}(t), i=1,2$ in Eq. (8) and we can have at most two equilibriums $E_{0}=\left(0,\left(a-c_{2}\right) / 2 b\right)$ and $E^{*}=\left(q_{1}^{*}, q_{2}^{*}\right)$. The fixed point $E_{0}$ is called a boundary equilibrium and have economic meaning when $c_{2}<a$. The second equilibrium $E^{*}$ is called Nash equilibrium where

$q_{1}^{*}=\frac{a+c_{2}-2 c_{1}}{3 b}, q_{2}^{*}=\frac{a+c_{1}-2 c_{2}}{3 b}$

provided that

$\left\{\begin{array}{l}2 c_{1}-c_{2}<a \\ 2 c_{2}-c_{1}<a\end{array}\right.$

The study of the local stability of equilibrium solutions is based on the localization on the complex plane of the eigenvalues of the Jacobian matrix of the two dimensional map (Eq. (8)). In order study the local stability of equilibrium points of the model (8), we consider the Jacobian matrix along the variable strategy $\left(q_{1}, q_{2}\right)$. According to [3] $E_{0}$ is saddle point of the system (8) and the Nash equilibrium $E^{*}$ is locally stable if the following conditions are hold

$$
\left\{\begin{array}{l}
\text { (i) } 1-T+D>0 \\
\text { (ii) } 1+T+D>0 \\
\text { (iii) } 1-D>0
\end{array}\right.
$$

where $\mathrm{T}$ is the trace and $\mathrm{D}$ is the determinant of the Jacobian matrix

$$
J\left(E^{*}\right)=\left[\begin{array}{cc}
1-2 u b q_{1}^{*} & -u b q_{1}^{*} \\
\frac{-v}{2} & 1-v
\end{array}\right]
$$

The first condition is always satisfied, whereas the other two conditions (ii) and (iii) define a bounded region of stability in the parameters space $(u, v)$. Then the second and third 
conditions are the conditions for the local stability of Nash equilibrium which becomes:

$$
\left\{\begin{array}{l}
2 v+4 u b q_{1}^{*}-\frac{3}{2} u v b q_{1}^{*}-4<0 \\
\frac{3}{2} u v b q_{1}^{*}-v-2 u b q_{1}^{*}<0
\end{array}\right.
$$

\section{Numerical simulations}

To provide some numerical evidence for the chaotic behavior of the system Eq. (8), as a consequence of change in the marginal costs of the players, we present various numerical results here to show the chaoticity, including its bifurcations diagrams, strange attractors, Lyapunov numbers, sensitive dependence on initial conditions [14]. In order to study the local stability properties of the equilibrium points, it is convenient to take the parameters values as follows: $a=10, b=0.5$ Numerical experiments are computed to show the bifurcation diagram with respect to $c_{1}, c_{2}$, strange attractor of the system (8) in the phase plane of the quantity outputs $\left(q_{1}, q_{2}\right)$, the Lyapunov numbers and the box dimension. Fig. 1a, 1b. shows the bifurcation diagrams with respect to the parameter $c_{1}$ and for $\mathrm{u}=0.45$, $\mathrm{v}=0.7, \mathrm{c}_{2}=3$. Fig. $2 \mathrm{a}, 2 \mathrm{~b}$. shows the bifurcation diagrams with respect to the parameter $c_{2}$ and for $\mathrm{u}=0.45, \mathrm{v}=0.7, \mathrm{c}_{1}=$ 5 . In these figures for small values of the parameter $c_{i}$ one observes complex dynamic behavior such as cycles of higher order and chaos. Fig. 3a show the graph of strange attractor and Fig. 3b. the Lyapounov numbers of the orbit of $(0.1,0.1)$ for $\mathrm{u}=0.5, \mathrm{v}=0.7, \mathrm{c}_{1}=2.5, \mathrm{c}_{2}=3$.

From these results when all parameters are fixed and only $c_{i}$ is varied the structure of the market of duopoly game becomes complicated through period doubling bifurcations, more complex bounded attractors are created which are aperiodic cycles of higher order or chaotic attractors.

\subsubsection{Sensitive dependence on initial conditions}

To demonstrate the sensitivity to initial conditions of the system (8), we compute two orbits with initial points $(0.1$, $0.2)$ and $(0.1,0.2001)$, respectively. The results are shown in Fig. 4a. and Fig. 4b. At the beginning the time series are indistinguishable; but after a number of iterations, the difference between them builds up rapidly. Fig. 4a. and Fig. $4 b$. shows sensitive dependence on initial conditions for $\mathrm{q}_{2}$-coordinate of the two orbits, for the system (8), plotted against the time with the parameters values $\mathrm{u}=0.45, \mathrm{v}=0.7$, $\mathrm{c}_{1}=2.5, \mathrm{c}_{2}=4$.

\subsubsection{Box Dimension}

One way to measure the complexity of a set (an orbit of the map) is to compute its dimension over different scales of magnification [14]. Let $\mathrm{S}$ a bounded set in ${ }^{\circ} m$ and $N(r)$ the minimum number of boxes of side-length $r$ needed to contain all the points of the set. The box dimension $\mathrm{BD}(\mathrm{S})$ of $\mathrm{S}$ is defined to be the number $\mathrm{d}$ that satisfies:

$$
N(r)=\lim _{r \rightarrow 0} k r^{-d}
$$

Where $\mathrm{k}$ is proportionality constant. In practice, we find $\mathrm{d}$ by taking the logarithm of both sides of Eq. (15) (before taking the limit) to find

$$
d=B D(S)=-\lim _{r \rightarrow 0} \frac{\ln N(r)}{\ln r}
$$

when the limit exists. In most cases, the only practical way of calculating the box dimension of an orbit is through numerical approximations. If $\mathrm{S}$ is the orbit of Fig. 3 and

$$
r=0.001, B D(S)=1.09998
$$

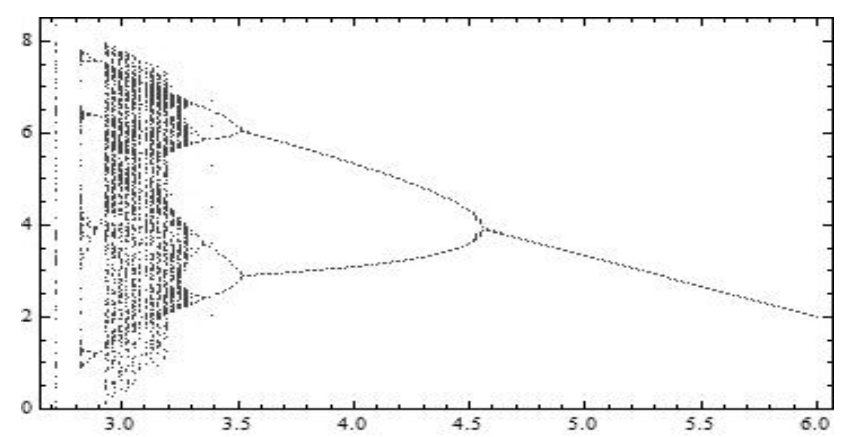

Fig.1a. Bifurcation diagram with respect to the parameter $c_{1}$ against variable $\mathrm{q}_{1}$ with 550 iterations of the map Eq. (8) for $\mathrm{u}=0.45, \mathrm{v}=0.7, \mathrm{c}_{2}=$ 5.

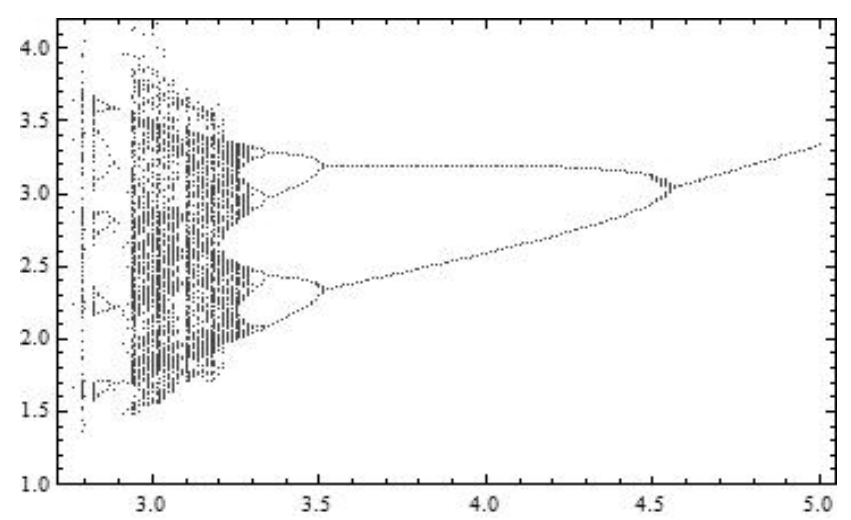

Fig.1b. Bifurcation diagram with respect to the parameter $c_{1}$ against variable $\mathrm{q}_{2}$ with 550 iterations of the map Eq. (8) for $\mathrm{u}=0.45, \mathrm{v}=0.7, \mathrm{c}_{2}=$ 5.

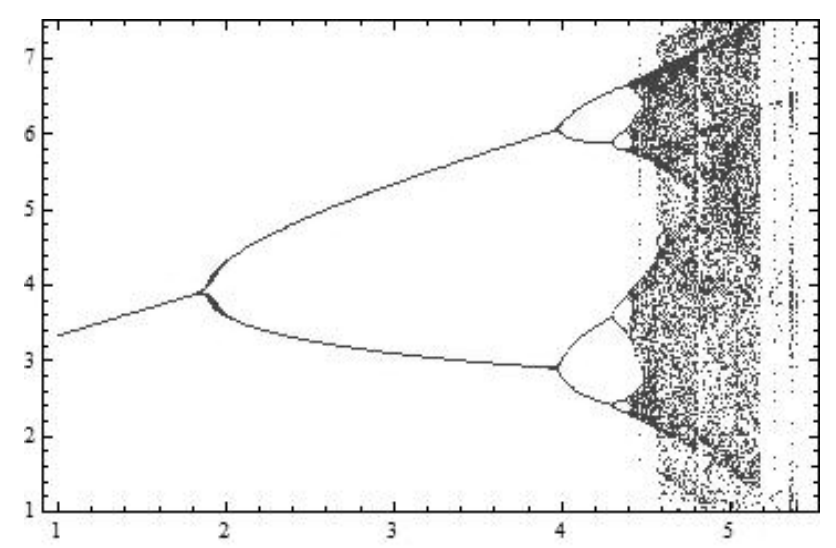

Fig.2a. Bifurcation diagram with respect to the parameter $c_{2}$ against variable $\mathrm{q}_{1}$ with 550 iterations of the map Eq. (8) for $\mathrm{u}=0.45, \mathrm{v}=0.7, \mathrm{c}_{1}=$ 3 


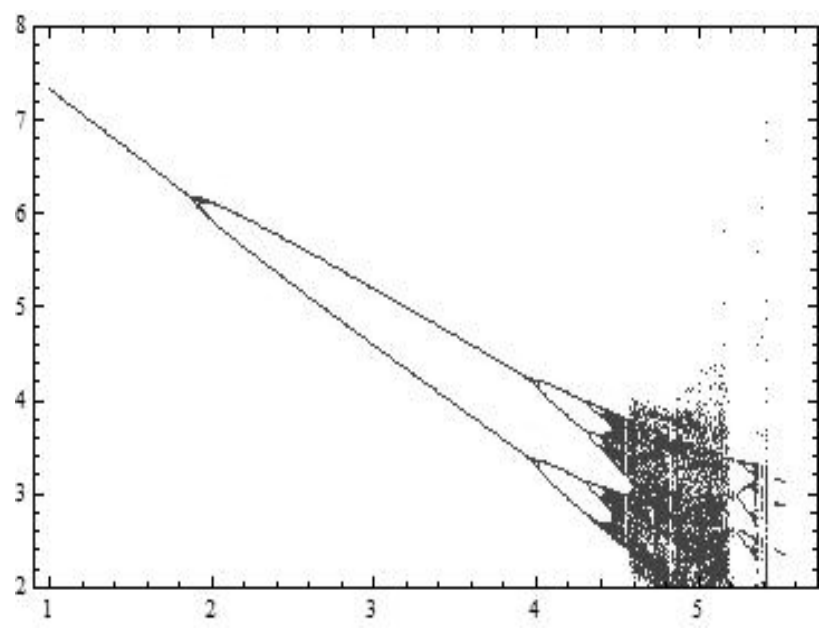

Fig.2b. Bifurcation diagram with respect to the parameter $c_{2}$ against variable $\mathrm{q}_{2}$ with 550 iterations of the map Eq. (8) for $\mathrm{u}=0.45, \mathrm{v}=0.7, \mathrm{c}_{1}=$ 3

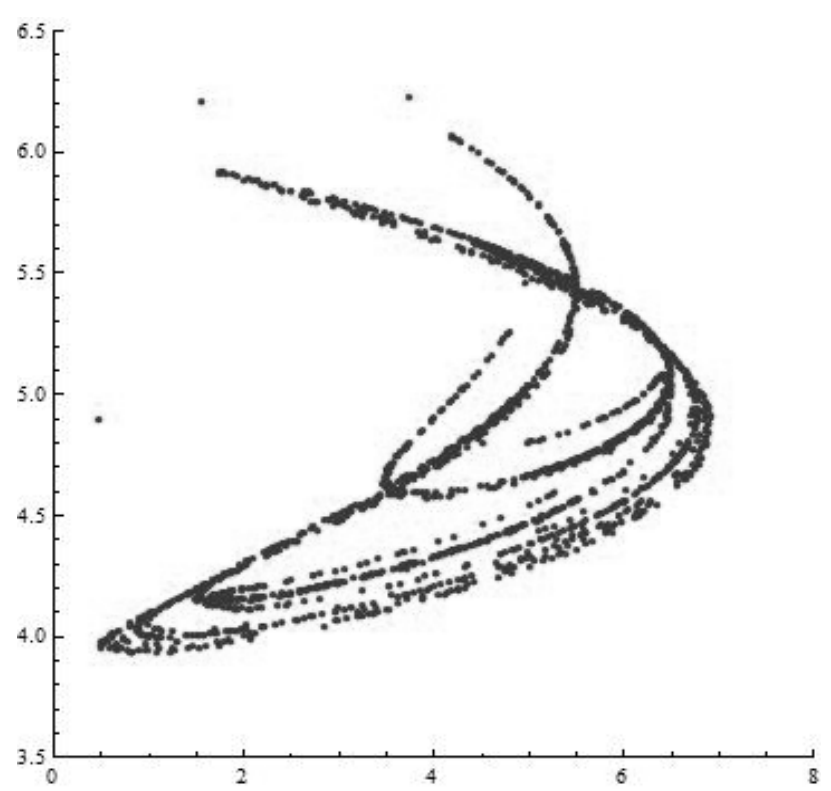

Fig.3a. Strange attractor with 2000 iterations of the map, with initial point $(0.1,0.1)$, for $\mathrm{u}=0.5, \mathrm{v}=0.7, \mathrm{c}_{1}=2.5, \mathrm{c}_{2}=3$.

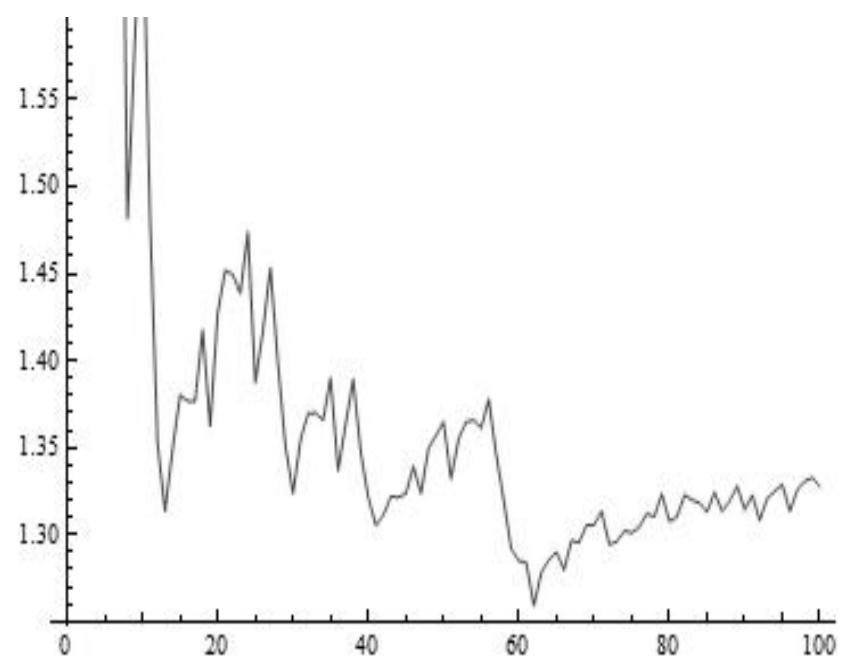

Fig.3b. Lyapunov numbers, versus the number of iterations, of the orbit orb. $(0.1,0.1)$, for $\mathrm{u}=0.5, \mathrm{v}=0.7, \mathrm{c}_{1}=2.5, \mathrm{c}_{2}=3$.

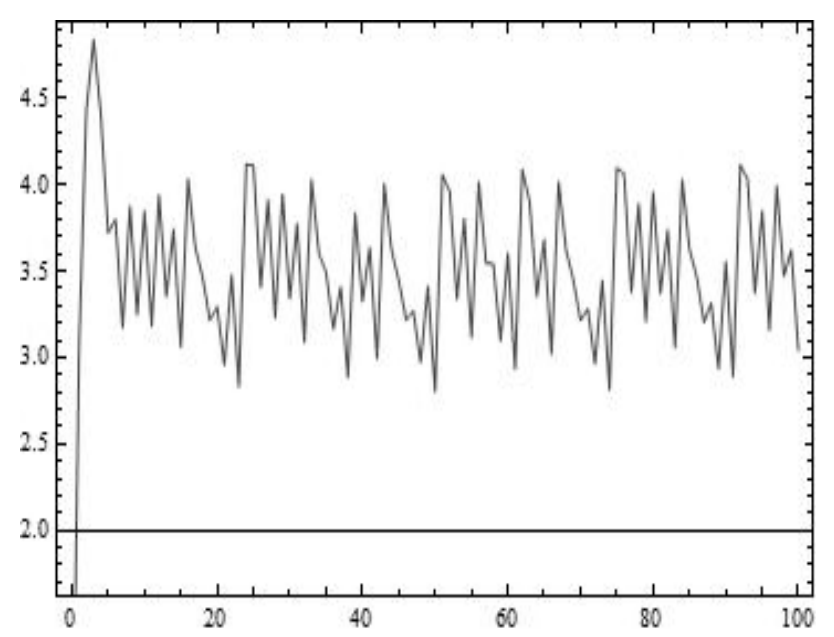

Fig.4a. Sensitive dependence on initial conditions, for $\mathrm{q}_{2}$-coordinate plotted against the time: The orbit of $(0.1,0.2)$, for the system $(8)$, with the parameters values $\mathrm{u}=0.45, \mathrm{v}=0.7, \mathrm{c}_{1}=2.5, \mathrm{c}_{2}=4$.

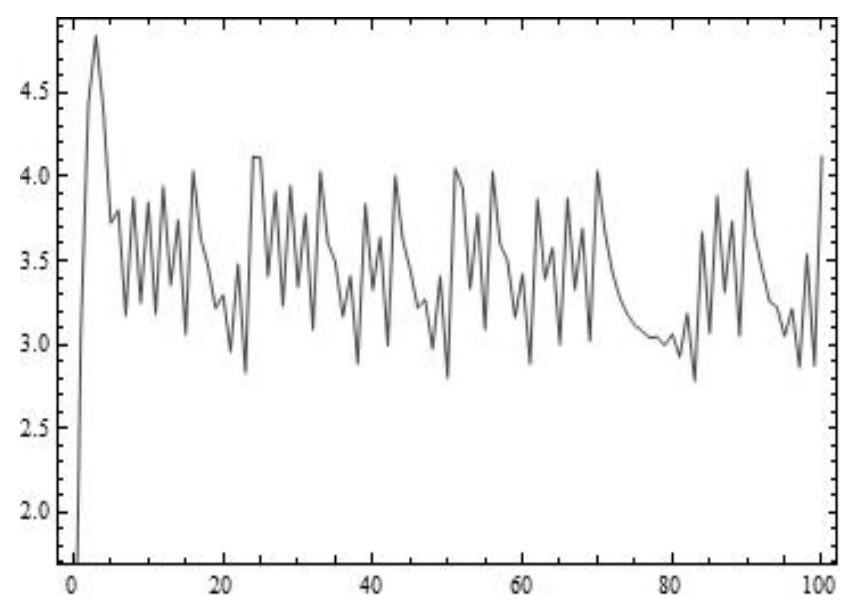

Fig.4b. Sensitive dependence on initial conditions, for $\mathrm{q}_{2}$-coordinate plotted against the time: The orbit of $(0.1,0.2001)$ for the system (8), with the parameters values $\mathrm{u}=0.45, \mathrm{v}=0.7, \mathrm{c}_{1}=2.5, \mathrm{c}_{2}=4$.

\section{Conclusion}

In this paper we proposed and analyzed the effect of the marginal cost in the dynamic behavior of a nonlinear duopoly game, which contains two-types of heterogeneous players: boundedly rational player and adaptive expectation player. We show that the parameter of the marginal cost may change the stability of the system and cause a structure to behave chaotically. For low (high) values of this parameter for the boundedly rational (adaptive) the system becomes instable, through period-doubling bifurcation.

\section{Acknowledgements}

The author thanks the two anonymous referees for interesting remarks and useful suggestions. 


\section{References}

[1]. Agiza HN. Explicit stability zones for Cournot games with 3 and 4 competitors. Chaos Solitons Fract. 1998;9: 1955-66.

[2]. Agiza HN. On the stability, bifurcations, chaos and chaos control of Kopel map. Chaos Solitons Fract. 1999;11: 1909-16.

[3]. Agiza HN, Elsadany AA. Chaotic dynamics in nonlinear duopoly game with heterogeneous players. Appl. Math. Comput. 2004;149: 843-60.

[4]. Agiza HN, Elsadany AA. Nonlinear dynamics in the Cournot duopoly game with heterogeneous players. Physica A 2003;320: 512-24.

[5]. Agiza HN, Hegazi AS, Elsadany AA. Complex dynamics and synchronization of duopoly game with bounded rationality. Math. Comput. Simulat. 2002; 58: 133-46.

[6]. Bischi GI, Kopel M. Equilibrium selection in a nonlinear duopoly game with adaptive expectations. J. Econom Behav. Org. 2001; 46: 73-100.

[7]. Bischi GI, Lamantia F, Sbragia L. Competition and cooperation in natural resources exploitation: an evolutionary game approach. In: Cararro C, Fragnelli V, editors. Game practice and the environment. Cheltenham: Edward Elgar; 2004. p. 187-211.

[8]. Bischi GI, Naimzada A. Global analysis of a dynamic duopoly game with bounded rationality. In: Filar JA, Gaitsgory V, Mizukami K, editors. Advances in dynamic games and applications, vol. 5. Basel: Birkhauser; 2000. p. 361-85.

[9]. Cournot A. Researches into the mathematical principles of the theory of wealth. Homewood (IL): Irwin; 1963.
[10]. Den Haan WJ. The importance of the number of different agents in a heterogeneous asset-pricing model. J. Econom. Dynam. Control 2001; 25:721-46.

[11]. Gandolfo G. Economic dynamics. Berlin: Springer; 1997.

[12]. Gao Y. Complex dynamics in a two dimensional noninvertible map. Chaos Solitons Fract. 2009;39: 1798-810.

[13]. Kopel M. Simple and complex adjustment dynamics in Cournot duopoly models. Chaos Solitons Fract. 1996; 12: 2031-48.

[14]. Kulenonic, M., Merino, O., Discrete Dynamical Systems and Difference Equations with Mathematica, Chapman \& Hall/Crc., 2002

[15]. Medio A, Gallo G. Chaotic dynamics: theory and applications to economics. Cambridge (MA): Cambridge University Press; 1995.

[16]. Medio A, Lines M. Introductory notes on the dynamics of linear and linearized systems. In: Lines M, editor. Nonlinear dynamical systems in economics. SpringerWienNewYork: CISM; 2005. p. 126.

[17]. Medio A, Lines M. Nonlinear dynamics. A primer. Cambridge (MA): Cambridge University Press; 2001.

[18]. Puu T. Chaos in duopoly pricing. Chaos Solitons Fract. 1991; $1: 573-81$.

[19]. Puu T. Complex oligopoly dynamics. In: Lines M, editor. Nonlinear dynamical systems in economics. Springer Wien NewYork: CISM; 2005. p. 165-86.

[20]. Puu T. The chaotic duopolists revisited. J. Econom. Behav. Org. 1998;37:385-94.

[21]. Tramontana F. Heterogeneous duopoly with isoelastic demand function. Econom. Modelling 2010;27:350-7. 